\title{
Undressing Fashion Metadata: Ryerson University Fashion Research Collection
}

\author{
Naomi Eichenlaub \\ Ryerson University, \\ Canada \\ neichenl@ryerson.ca
}

\author{
Marina Morgan \\ Ryerson University, \\ Canada \\ marina.morgan@ryerson.ca
}

\author{
Ingrid Masak-Mida \\ Ryerson University, \\ Canada \\ ingrid.masakmida@ryerson.ca
}

Keywords: fashion; metadata schema; metadata mapping; cataloguing; digital collections; digitization; Dublin Core; VRA Core.

\section{Abstract}

The purpose of this poster is to provide insight into the processes involved in making a unique fashion research and teaching collection discoverable in an online environment at Ryerson University. The online collection will provide a means for the users to identify what artifacts are available for research purposes and facilitate teaching in the classroom. The poster will highlight effective metadata standards and elements, cross-domain metadata uses, metadata mapping and implementation

\section{Introduction}

Ryerson University Fashion Research Collection project, a collaboration between the School of Fashion at Ryerson University and RULA (Ryerson University Library and Archives), consists of creating an online collection of images and metadata representing several thousand donated garments and accessories, designer clothing and millinery donated from private collections dating back to the latter part of the nineteenth century and early 20th century.

The key goals of this online collection are to promote research, teaching and learning at Ryerson University, and to connect with a broader community by building scholarly, online exhibitions. Once finalized, it will be used as a pedagogical tool and it will inspire fashion students and scholars to undertake research into fashion history.

\section{Background}

Ryerson University Library and Archives has partnered with the Ryerson School of Fashion to increase access to a unique collection of fashion items. The collection was housed in unfavourable conditions in a locked room in the library for many years and was relatively unknown to students. It was recently relocated to a series of rooms in the School of Fashion building. The collection is now in the process of being curated by its collection coordinator, who received a grant to digitize a portion of the collection in 2012. Currently, only very limited amount of information is available about the Ryerson Fashion Research Collection through a blog and a Pinterest site. Initially, a sample of the collection was loaded on to Pinterest as a means of both engaging students as well as exposing the collection to the world. The social media platform, however, has limited search functionality and virtually no descriptive metadata beyond an item description box.

Zeng (2009) asserts that the physical access restrictions common to most collections of historical fashion result from "delicate artifacts and by the inaccessible nature of many costume collection storage facilities". The online collection, however, will increase access from what was once multiple sets of excel spreadsheets of described items onto a searchable platform that will 
allow students, faculty and staff to have a more robust discovery, searching and browsing experience.

\section{Research Significance}

The research significance of the Ryerson Fashion Research Collection is three-fold. First, it will provide a venue for a greater expanse of fashion online exhibits, a pedagogical tool that will allow Ryerson students to learn and research, to foster students' interaction and participation, and to explore a rich yet previously inaccessible fashion collection at Ryerson University. Second, it will allow us to build on and implement future specific collections, to foster a connection between external and internal users, to promote and improve online access that would add value to the existing collection. Third, digital access will preserve the valuable collection, but at the same time will allow researchers, students, and the public to have "visual access to an entire collection without needlessly disturbing the garments and their accessories" (Zeng, 1999).

\section{Metadata Implementation and Challenges}

Very little has been written or published about the digitization of fashion collections and specifically about appropriate metadata schema for optimizing access and discovery of fashion object collections. The question of appropriate descriptive elements for use in fashion collection metadata records was noted by Marcia Lei Zeng in her article Metadata elements for object description and representation: a case report from a digitized historical fashion collection project specifically due to the three-dimensional nature of fashion artifacts (Zeng, 1999).

As Lampert and Chung (2011) argued, before developing and designing a digital collection, there are various technical questions to consider, such as thoroughly assessing various feature sets of different systems and making informed decisions to seek out appropriate solutions. Consequently, we evaluated and analyzed several web-publishing platforms, both proprietary and open source, and metadata standards that would better fit our criteria. Simplicity of installation of the software and metadata ingest were very important to us, particularly since we were working within a fairly short timeline. As well, metadata adaptability and interoperability, import and export functionality of specific standard data formats, flexible approaches to various plug-ins, (specifically the OAI-PMH Harvester) factored in to our selection criteria.

Judging against our expectations, we evaluated three possibilities that would best fit the selection criteria mentioned above: ICA-AtoM, SharedShelf (ARTstor), and Omeka.

\begin{tabular}{|l|l|l|l|l|l|}
\hline & $\begin{array}{l}\text { Metadata } \\
\text { Standard }\end{array}$ & Customizable & $\begin{array}{l}\text { One to Many } \\
\text { Relationship }\end{array}$ & OAI-PMH & Cost \\
\hline Atom & Various & No & No & Yes & Free \\
\hline SharedShelf (ARTstor) & VRA Core & Yes & No & Yes & Subscription \\
\hline Omeka & Dublin Core VRA & Yes & Yes & Yes & Free \\
\hline
\end{tabular}

Fig. 1 Comparison of possible web publishing platforms and metadata standards

AtoM (Access to Memory) is a web-based, dynamic open source application for standardsbased archival description and access, allowing various import and export formats, and supporting ICA and non-ICA standards (RAD, Dublin Core, and MODS). Shared Shelf is a media management software that enables management, storage, use, and publishing institutional and faculty media collections within their institution, or publicly on the Web. Though highly customizable, complex and flexible, the platform did not allow for multiple image batch loading per individual item described (one-to-many relationships). 
Omeka, a free, flexible, and open source web-publishing platform, on the other hand, allows the expansion of its core functionality with existing plugins to create maps, to allow users to tag favorites, and to create dynamic and robust online exhibits, thus tying closely with the pedagogical requirements of this project.

There are several other products on the market that offer features similar to Omeka. However, when it comes to providing the rich visual context or exhibiting collections, as today's web users would expect, these platforms may be less effective, often difficult to adopt, and more expensive to maintain than Omeka. Motivated to create digital collections due to the educational imperative to share their collections with the public, the academic world is often facing "restricted budgets and staffing issues" as Sauro (2009) argues. Faced with the same budget and staffing restrictions, we decided to go with the most flexible and cost effective solution for our project, Omeka. The decision was also based on the variety of features that Omeka offers. As highlighted by Kucsma, Reiss, and Sidman (2010), Omeka allows strong and flexible approach to metadata representation, straightforward plug-in deployment, customs creation of item types, and the addition of the full set of Dublin Core properties to the existing Dublin Core element set, including element refinements and supplemental elements.

Metadata element selection and metadata mapping was the next challenge. Selecting the metadata elements and refining the specifications is closely tied to the end-user usage patterns and item description choices. The stakeholders (users, faculty, and digital collection creators) have different ideas about what is useful in the collection. We learned that faculty use the collection for their own research as well as to enhance classroom learning; external researchers, visiting scholars, and curators are interested in a particular designer, period or type of artifact (e.g. 19th century hair accessories). We also learned that students seek access to the collection in different ways: to establish the specific material of a garment, or identify the type of stitching or other manufacture processes. Although the search strategy depends on the research question being asked, in general the primary search terms would be for a particular type of garment (corset, dress, coat, hat), period (1920s, 1950s, 1960s), designer (Balenciaga, Dior, Balmain), construction type (bias cut, inset sleeves), colour (yellow, orange, red), or textile (silk, linen, cotton). Consequently, we had consulted with the curator in order to determine the metadata elements highlighting the benefits of certain metadata elements. This possible usage pattern directly influenced the item description and metadata elements. What fits the faculty curricula vs. what fits the interest of the student or researcher directly impacted those choices.

Zeng (1999) references difficulty of locating appropriate text to use as a title, an issue we faced as well. Discussion of the requirement for a title in each record was necessary, as it was understood that students would often be searching by accession number instead of title. Consequently, the curator of the Ryerson Fashion Collection created titles for each item using her expert knowledge in the field, adding mostly general terms such as "evening dress", followed in most cases by slightly more specific terms including the gender, colour, or shape of the garment, for example "Green wool men's tailcoat with black satin lapel and black wool vest".

Equally important when working with the metadata for these fashion items is the information needs of the students using the collection. In terms of providing subject access to the collection, after some discussion regarding the merits of additional subject access points we agreed that we would use the Art \& Architecture Thesaurus (Getty Research Institute) (AAT). We had also considered using the Thesaurus of Graphic Materials (TGM) or Library of Congress (LC) Subjects, but our examination of fashion headings in the AAT revealed that it had better coverage in terms of fashion subject specificity. For example, the AAT has a term for dresses (garments) under which there are more than a dozen narrower terms including chemise dresses, coat dresses, gowns, jumpers (dresses), maxi dresses, midi dresses, muumuus, overdresses, etc. However, there are also limitations. For example, in using the AAT as it currently exists, certain commonly used terms for garments such as the word "pants" or "tunic" cannot be used. Consequently, to make items more discoverable, we used the tagging option in Omeka. 
There were a number of other metadata fields that posed some challenges in order to meet the information needs of the students, while respecting the descriptive standards we were following. Rich description and details ended up mostly being mapped to one DC element: DESCRIPTION. VRA Core elements such as MATERIAL, MEASUREMENTS, CULTURE, OR STYLE/PERIOD would seem more appropriate given the specificity of this collection. Omeka does have the option of implementing the VraCoreElementSet plugin developed by the Scholars' Lab at the University of Virginia Library. Given the time and staffing constraints we haven't been able to configure and test it, however, this is something that we could develop in the future.

Batch image loading and one-to-many relationships was another challenge we faced. To be able to accomplish this task, we had two options: one was to use the OAI data to create a CSV instead of using it to import directly into Omeka. This would allow us to add a column to the CSV file with the location of the files for each item. The second option was to loop through the images and identify the correct object ID, i.e. the description to which the image

will be linked. A script looped through each line of the CSV file, stored the accession number into a variable, and for each accession number it looped through the filenames, adding only the matching filenames at the end of the line in the CSV. When opening the resulting CSV, a new column containing the matching filenames was created, thus allowing a smooth batch loading of images and item description, including the metadata.

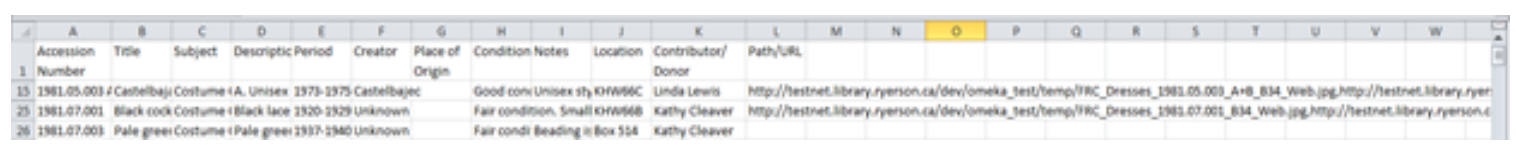

FIG. 2 Example of extra column added after executing the scripts

The last challenge was the collection's discoverability. Necessary for a quality user experience, the Fashion Research Collection should be seamlessly available via the library's discovery layer. However, this collection is not yet integrated into the library's discovery environment. In order for this collection to be discovered, a record in the library catalogue and one in the University's repository will be created.

\section{Future Research}

Looking to the future, a number of international digital fashion collection projects provide inspiration for the possibility of a similar Canadian initiative. The Europeana Fashion Portal is a three-year project to aggregate best of Europe's fashion collections and has a number of goals including improving interoperability and developing a specialized Fashion Thesaurus. ${ }^{1}$ Australia also has a national initiative called the Australian Dress Register which showcases pre-1975 dress with Australian provenance and encourages museums and private collectors to "research their garments and share the stories and photographs while the information is still available and within living memory".2

Of particular relevance to future directions for online fashion resources is the possibility of incorporating interactive functionality and social features into collections to allow for usergenerated content (Lampert, 2011). Allowing users to contribute their knowledge about historical items of little-known provenance, for example through tagging, can be an effective way to gather information that collection curators might otherwise miss. Moreover, incorporating some of the functionality of social curation sites such as Pinterest that allow for users to create their own personal digital collections is another possible future direction. The Omeka software has a

\footnotetext{
${ }^{1}$ http://blog.europeanafashion.eu/about/).

$2 \mathrm{http}: / /$ www.australiandressregister.org/about/
} 
number of plugins that offer a level of user interaction, such as the Comments, Exhibit Builder and MyOmeka, the latter allowing for item favouriting.

\section{Conclusions}

The Fashion Research Collection is a study collection consisting of several thousand artifacts including garments, accessories, and ephemera including photographs, magazines, and patterns. This collection is intended to support the research activities of the students and faculty at Ryerson University as well as means of engaging the outside community. This project met its overarching goals of increasing access and discoverability to a unique collection of mixed-provenance but mostly Canadian fashion items. Furthermore, the collaboration between the School of Fashion and Ryerson University Library and Archives allowed for subject matter experts in fashion, cataloguing and metadata standards to collaborate on a project that will provide community members and the public-alike with access to a tool for research, teaching, and learning.

\section{References}

Artstor Digital Library. (2014). Shared Shelf Features. Retrieved from

http://www.artstor.org/shared-shelf/s-html/features.shtml

Dublin Core Metadata Initiative. (2012). DCMI Metadata Terms. Retrieved from

http://dublincore.org/documents/dcmi-terms/

ICA-AtoM. Retrieved from https://www.ica-atom.org

Kucsma, J., Reiss, K., \& Sidman, A. (2010). Using Omeka to build digital collections: The METRO case study. D-Lib Magazine, 16(3/4) doi:10.1045/march2010-kucsma

Lampert, C. \& Chung, S.K. (2011). Strategic planning for sustaining user-generated content in digital collections. Journal of Library Innovation, 2(2), 74-93.

Omeka Plugins. (2014). Retrieved from http://omeka.org/add-ons/plugins/

Sauro, C. (2009). Digitized historic costume collections: Inspiring the future while preserving the past. Journal of the American Society for Information Science and Technology, 60(9), 1939-1941. doi:10.1002/asi.21137

Tzoc, E., \& Millard, J. (2011). Technical skills for new digital librarians. Library Hi Tech News, 28(8), 11-15. doi:10.1108/07419051111187851

Valentino, M. L. (2010). Integrating metadata creation into catalog workflow. Cataloging \& Classification Quarterly, 48(6-7), 541-550. doi:10.1080/01639374.2010.496304

VRA Core Schemas and Documentation. (2007). Retrieved from http://www.loc.gov/standards/vracore/VRA_Core4_Element_Description.pdf

Zeng, M. L. (1999). Metadata elements for object description and representation: A case report from a digitized historical fashion collection project. Journal of the American Society for Information Science, 50(13), 1193. 